\title{
New labels to curb opioid abuse
}

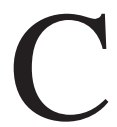

anada's growing prescription drug abuse problem is "unacceptable," Federal Health Minister Rona Ambrose told delegates to the Canadian Medical Association's (CMA's) annual meeting in Ottawa Aug. 18.

She announced label changes to enhance the safety and appropriate use of controlled-release opioids, including oxycodone and fentanyl products. Ambrose said the new labels will "more clearly outline the risks and safety concerns associated with these medicines," including a warning that the drugs should only be used to manage severe pain.

"We know that Canada is now the second largest per capita consumer of prescription opioids, exceeded only by the United States," she said. Some 410000 Canadians report abusing a wide range of prescription drugs, Ambrose added. These include "pain relievers such as Demerol and Oxycontin, stimulants such as Ritalin and Adderall, and tranquilizers such as Valium, Ativan and Xanax."

"These numbers are frightening," she said. "We must work together to develop practical solutions that will prevent abuse while keeping medications available for patients who need them."

To that end, the federal government has committed \$45 million in this year's budget to expand Canada's anti-drug strategy to include prescription drug abuse. Ambrose also cited ongoing efforts to regulate tamper-resistant ingredients that would prevent certain opioids from being "crushed, snorted or injected."

The past year has also seen "real progress" in improving the review and safety of prescription drugs, said Ambrose. With the impending passage of "Vanessa's law," the federal government will soon have the power to recall unsafe drugs from market. The bill will also empower regulators to compel drug

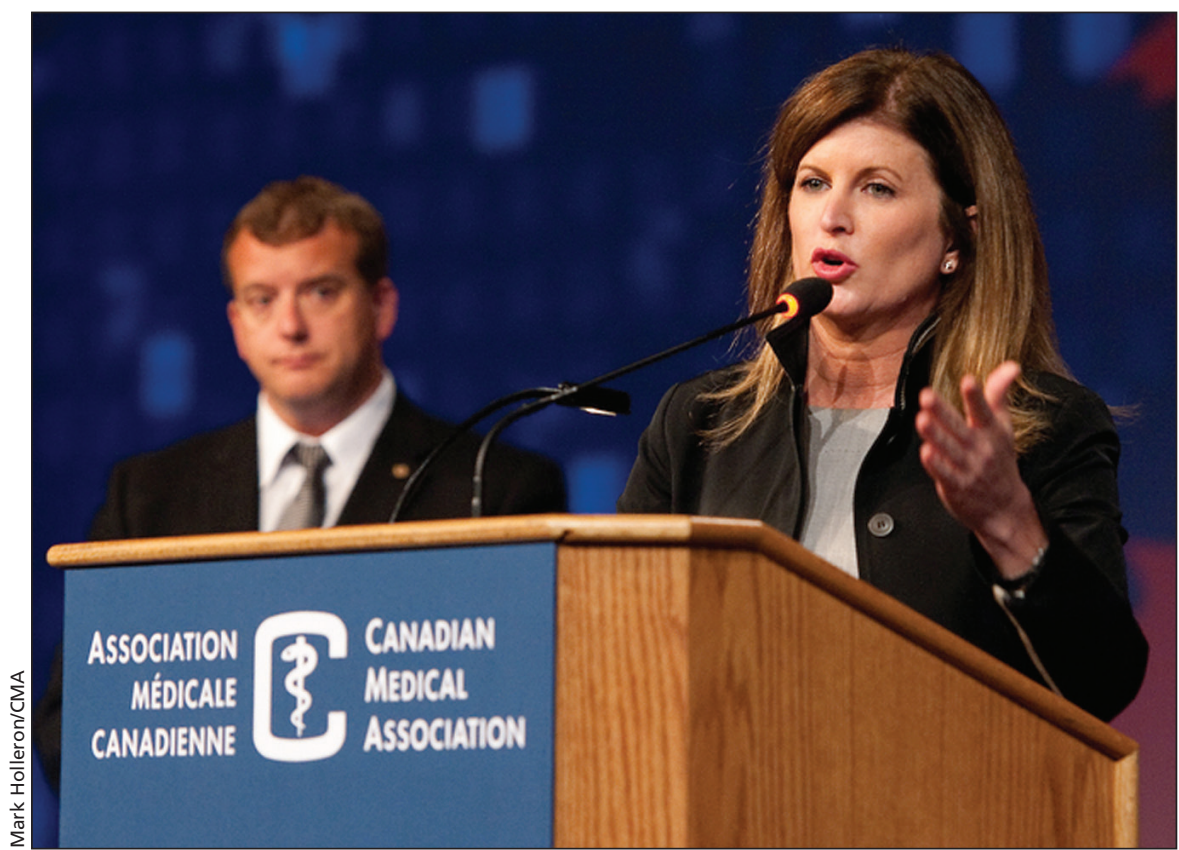

Government and doctors must work together to solve Canada's prescription drug abuse problem, says Federal Minister of Health Rona Ambrose.

companies to revise labels to clearly reflect health risks, and do further testing on products when issues are identified for certain at-risk populations, such as children.

At a press conference following her address to the CMA, Ambrose responded to concerns about Canada's new medical marijuana regimen. Although she acknowledged that "doctors are in a precarious situation [prescribing pot], just as Health Canada was when it dealt with the issue," Ambrose contended that the new strategy is working and that doctors are best placed to make decisions with their patients.

Ambrose also spoke of the importance of the government's relationship with the CMA and its role as a source of innovative ideas and practices, highlighting its involvement in Choosing Wisely Canada.

"With all the new technology that's available, it's understandable for patients in health-threatening situations to seek any and all diagnostic tools, but most will choose rationally if they are fully informed about which tools are necessary and appropriate," she said. "With an aging population and the growing burden of chronic disease, we also know we need to accelerate the pace of progress on innovation."

In June, Ambrose appointed a health care innovation panel. Headed by a medical researcher and former president of the University of Toronto, Dr. David Naylor, the panel will meet with provincial and territorial governments, health groups and patients over the next 10 months.

Ambrose also emphasized the importance of physicians practising what they preach to their patients. "Whether it's being active, eating healthy or not smoking ... all of us have a responsibility as role models to encourage the younger generation." - Lauren Vogel, CMAJ

CMAJ 2014. DOI:10.1503/cmaj.109-4877 